\title{
Divergent regulation of IncRNA expression by ischemia in adult and aging mice
}

\author{
Tamás Kaucsár · Beáta Róka • Pál Tod • \\ Phuong Thanh Do $\cdot$ Zoltán Hegedúis · \\ Gábor Szénási · Péter Hamar (iD)
}

Received: 15 February 2021 / Accepted: 11 September 2021 / Published online: 26 October 2021

(C) The Author(s) 2021

\begin{abstract}
Elderly patients have increased susceptibility to acute kidney injury (AKI). Long noncoding RNAs (IncRNA) are key regulators of cellular processes, and have been implicated in both aging and AKI. Our aim was to study the effects of aging and ischemia-reperfusion injury (IRI) on the renal expression of lncRNAs. Adult and old (10- and 26-30-month-old) C57BL/6 N mice were subjected to unilateral IRI followed by 7 days of reperfusion. Renal expression of 90 lncRNAs and mRNA expression of injury, regeneration, and fibrosis markers was
\end{abstract}

Gábor Szénási and Péter Hamar contributed equally.

Supplementary Information The online version contains supplementary material available at https://doi. org/10.1007/s11357-021-00460-9.

T. Kaucsár · B. Róka · P. Tod · P. T. Do · G. Szénási ·

P. Hamar

Institute of Translational Medicine, Semmelweis

University, Budapest, Hungary

P. Tod · P. Hamar $(\bowtie)$

Institute for Translational Medicine, Medical School, University of Pécs, Pécs, Hungary

e-mail: hamar.peter@med.semmelweis-univ.hu

\section{Z. Hegedűs}

Institute of Biophysics, Biological Research Centre, Eötvös

Loránd Research Network (ELKH), Szeged, Hungary

\section{Z. Hegedús}

Department of Biochemistry and Medical Chemistry,

Medical School, University of Pécs, Pécs, Hungary measured by qPCR in the injured and contralateral control kidneys. Tubular injury, regeneration, and fibrosis were assessed by histology. Urinary lipocalin-2 excretion was increased in old mice prior to IRI, but plasma urea was similar. In the control kidneys of old mice tubular cell necrosis and apoptosis, mRNA expression of kidney injury molecule-1, fibronectin-1, p16, and p21 was elevated. IRI increased plasma urea concentration only in old mice, but injury, regeneration, and fibrosis scores and their mRNA markers were similar in both age groups. AK082072 and Y lncRNAs were upregulated, while H19 and RepA transcript were downregulated in the control kidneys of old mice. IRI upregulated Miat, Igf2as, SNHG5, SNHG6, RNCR3, Malat1, Air, Linc1633, and Neat1 v1, while downregulated Linc1242. LncRNAs H19, AK082072, RepA transcript, and Six3os were influenced by both aging and IRI. Our results indicate that both aging and IRI alter renal lncRNA expression suggesting that lncRNAs have a versatile and complex role in aging and kidney injury. An Ingenuity Pathway Analysis highlighted that the most downregulated H19 may be linked to aging/senescence through p53.

Keywords lncRNA - Acute kidney injury · Ischemia-reperfusion injury 


\section{Introduction}

Acute kidney injury (AKI) has an increasing incidence worldwide, placing a continuously growing burden on the health care systems [1]. The aging of the population is a major cause of the growing number of AKI cases [2]. AKI is associated with elevated short- and long-term mortality and higher risks for developing chronic kidney disease (CKD) leading to end-stage renal disease (ESRD) in all age groups [1]. However, recovery of renal function is significantly worse in elderly patients [3], who require dialysis more often [2].

Old age is one of the main risk factors for AKI $[1,2]$. Elderly patients often have many comorbidities and take numerous medications including potentially nephrotoxic ones [2]. Even in the absence of these risk factors, the kidney becomes more susceptible to severe damage with advancing age as kidney function, the renal reserve, and the regenerative capacity decrease during normal aging $[2,4]$. Similarly to humans, aged mice and rats are more susceptible to AKI, including renal ischemia and reperfusion injury (IRI) [5-8], the leading cause of AKI [9].

Long noncoding RNAs (lncRNA) are non-proteincoding RNA transcripts of more than 200 nucleotides in length [10]. LncRNAs regulate all kinds of cellular and biological functions, from development, differentiation and proliferation to cell survival and death [11]. The regulatory function of IncRNAs is mediated by diverse mechanisms such as participation in scaffold formation, influencing cellular localization and activity of proteins and regulation of gene expression at all levels (epigenetic, transcriptional, and post-transcriptional) including genomic imprinting, X-inactivation, translation, and stability of mRNAs [10, 11].

Dysregulation of IncRNAs has been demonstrated in many pathological conditions. Likewise, lncRNAs have been implicated in several types of kidney diseases, including AKI and renal fibrosis $[12,13]$. Several lncRNAs were shown to modify renal fibrosis and inflammation by regulating the TGF- $\beta$ /Smad3 pathway [14-18]. LncRNA profiling was only performed in HK-2 and proximal tubular epithelial cells under hypoxic conditions [19, 20], while little is known about the functional involvement of lncRNAs in renal IRI, in vivo.
LncRNAs play important roles in the aging process. LncRNAs regulate cellular senescence, which has a central role in aging [21]. Many cellular processes that trigger either replicative or premature (upon damage) senescence are under IncRNA control, such as telomere shortening, genomic instability, oxidative stress, expression of senescence-regulatory tumor suppressor genes such as cyclin-dependent kinase inhibitor 2A (p16), cyclin-dependent kinase inhibitor 1 (p21) and cyclin-dependent kinase inhibitor $1 \mathrm{~B}$ (p27), and senescence-associated secretory phenotype [11,21].

To our knowledge, there is no data on the lncRNA response to renal IRI in old age. Therefore, our aim was to study the effects of both aging and unilateral IRI on the renal expression of lncRNAs.

\section{Methods}

Animal studies

Male C57BL/6 (Charles River Laboratories, Sulzfeld, Germany) mice were maintained under standardized (light on 08:00-20:00 h; 40-70\% relative humidity, $22 \pm 1{ }^{\circ} \mathrm{C}$ ), specified pathogen-free (SPF) conditions, with free access to standard rodent chow (Altromin standard diet, Altromin International, Lage, Germany) and tap water. All procedures were performed in accordance with guidelines set by the National Institutes of Health (USA), the Hungarian law on animal care and protection. All protocols were approved by the Committee on Animal Welfare of Semmelweis University and the Pest County Government Office (registration numbers: XIV-I-001/2103-4/2012 and 22.1/321/3/2011).

Ischemia-reperfusion surgery

Experiments were performed on 10-month-old (adult) $(n=7)$ and 26-30-month-old (old) mice $(n=8)$. Since aged C57BL/6 mice may develop malignancies, we examined all mice and excluded those with tumors from the study.

All mice were subjected to unilateral renal ischemia-reperfusion injury (IRI) as described previously [22-24]. Briefly, the experiments were carried out using standard operating procedures. The intra-abdominal temperature was maintained using 
a heating pad (Supertech Ltd., Pécs, Hungary). The animals were anesthetized by an intraperitoneal (ip.) injection of $80 \mathrm{mg} / \mathrm{kg}$ of bodyweight ketamine (CPPharma Handelsgesellschaft mbH, Burgdorf, Germany) and $4 \mathrm{mg} / \mathrm{kg}$ of bodyweight xylazine cocktail (CP-Pharma Handelsgesellschaft $\mathrm{mbH}$, Burgdorf, Germany). After median laparotomy, the left renal pedicle was exposed and the renal artery and vein were clamped for $20 \mathrm{~min}$. The right kidney was left undisturbed and was used for control purposes in all experiments. Postoperative care included morphine hydrochloride $(2.5 \mathrm{mg} / \mathrm{kg}$ of bodyweight subcutaneous (sc.) injection after the operation) analgesia and ceftriaxone (Rocephin (Roche Hungary Ltd., Budaörs, Hungary), $20 \mathrm{mg} / \mathrm{kg}$ of bodyweight sc. once after surgery) to prevent infectious complications.

\section{Organ harvest}

The experiments were terminated 7 days after IRI. Mice were injected with $5000 \mathrm{U} / \mathrm{kg}$ of bodyweight heparin i.p. (Ratiopharm GmbH, Ulm, Germany) and 3 min later, they were sacrificed by cervical dislocation. The chest was opened and after cross-section of the vena cava, blood was collected from the thoracic cavity. Blood was washed out of the whole circulation and the parenchymal organs by injecting $10 \mathrm{~mL}$ $4{ }^{\circ} \mathrm{C}$ saline transcardially. The kidneys were removed and decapsulated. The upper third part of the kidneys was placed in $500 \mu \mathrm{l}$ TRI Reagent (TR 118, Molecular Research Center, Inc., Cincinnati, OH, USA), was snap frozen in liquid nitrogen, and kept at $-80{ }^{\circ} \mathrm{C}$ for RNA isolation. A 1-mm-thick cross-section of the kidney at the hilus level including all layers of cortex and medulla was fixed in $4 \%$ buffered formaldehyde. The next day it was dehydrated and embedded in paraffin (FFPE) for histological analysis. The remaining parts of the kidney were cut into pieces, snap frozen in liquid nitrogen, and kept at $-80{ }^{\circ} \mathrm{C}$ for molecular biologic analysis.

\section{Urinary creatinine and Lcn-2 measurements}

Spot-urine was collected from mice on days $-1,1$, 3 , and 7. Urine samples were centrifuged (3000 g, $20 \mathrm{~min}, 4{ }^{\circ} \mathrm{C}$ ) to remove the sediment, and were stored at $-20{ }^{\circ} \mathrm{C}$.
Urine creatinine concentration was assessed with a colorimetric, enzymatic assay (Diagnosticum Ltd. Budapest, Hungary) in 96-well plates (Greiner BioOne $\mathrm{GmbH}$, Frickenhausen, Germany) according to the manufacturer's instructions as described previously [25]. Optical density was measured at $555 \mathrm{~nm}$ with the SpectraMax 340 Microplate Spectrophotometer (Molecular Devices, Sunnyvale, USA). Concentrations were calculated with SoftMax ${ }^{\circledR}$ Pro Software (Molecular Devices, Sunnyvale, USA).

Lipocalin-2 (Lcn-2, also called neutrophil gelatinase associated lipocalin (NGAL)) has been demonstrated to be a sensitive marker of tubular epithelial damage $[25,26]$. The urinary and plasma Lcn- 2 concentrations were determined with a mouse Lipocalin-2/NGAL DuoSet ELISA Development kit (R\&D Systems, Inc., Minneapolis, UK) as described previously [25]. Samples were measured in duplicates. The optical density was measured with Victor3 1420 Multilabel Counter (PerkinElmer, Waltham, MA, USA) at $450 \mathrm{~nm}$ with wavelength correction set to $544 \mathrm{~nm}$. The Lcn-2 concentrations were calculated with WorkOut software (Dazdaq Ltd., Brighton, UK), using a four-parameter logistic curve-fit. Urinary Lcn-2 concentrations were normalized to urinary creatinine concentrations.

\section{Plasma urea determination}

Approximately $100 \mu \mathrm{l}$ of blood was collected from the tail vein of mice on days $-1,1$, and 3 . On day 7 , blood was collected as described above. Plasma was separated by centrifugation (6000 g, $2 \mathrm{~min}$ ) and stored at $-80^{\circ} \mathrm{C}$.

Plasma urea concentrations were measured by a urease and glutamate-dehydrogenase enzymatic assay with colorimetric detection at $340 \mathrm{~nm}$ according to the manufacturer's protocol (Diagnosticum Zrt., Budapest, Hungary) and determined using a standard curve.

\section{Histology}

Renal tubule injury, apoptosis, regeneration, and inflammation in the outer stripe (OS) were evaluated in 4-mm thick hematoxylin-eosin (HE)-stained sections. Renal tubule injury was assessed based on tubule dilation, casts, and signs of necrosis (cell and 
nuclear swelling, pale cytoplasm, nuclear dissolution). Apoptotic cells were identified as smaller cells with cytoplasmic condensation (hypereosinophilic cytoplasm), and pyknotic and fragmented nuclei [27]. Regeneration score was based on tubular cells with large nuclei and mitotic cells. Inflammation was determined by the degree of infiltration by mononuclear cells. A histological score of 0 to 4 was given blinded to the origin of the tissue as follows: 0: no lesion, 1: minimal or focal changes affecting less than $20 \%$ of the OS, 2: mild changes or the extension of the lesion/regeneration to approximately $25 \%$ of the OS, 3: moderate changes or the extension of the lesion/regeneration to less than $66 \%$ of the OS, 4 : severe changes or the extension of the lesion/regeneration to more than $66 \%$ of the OS.

The extent of interstitial fibrosis in the OS was investigated on Masson's trichrome stained sections. A fibrosis score of 0 to 4 was given blinded to the origin of the tissue as follows: 0: no pathologic interstitial fibrosis, interstitial fibrotic (blue fibers) deposition in $1-25 \%$ of the field of view (score 1), 26-50\% (score 2), 51-75\% (score 3), 76-100\% (score 4).

RNA isolation and quantitative real-time PCR measurements of mRNA expression

Total RNA was extracted from the upper third of the kidney with TRI Reagent ${ }^{\circledR}$ (Molecular Research Center, Inc., Cincinnati, OH, USA) according to the protocol provided by the manufacturer (Chomczynski, 1993). The RNA pellet was dissolved in
$100 \mathrm{~mL}$ RNase-free water. The RNA concentration and purity was inspected with NanoDrop 2000c spectrophotometer (Thermo Fisher Scientific, Waltham, MA, USA). To investigate RNA integrity, samples were electrophoresed on native $1 \%$ agarose gel (Invitrogen Ltd., Paisley, UK) and the 28S and $18 \mathrm{~S}$ ribosomal RNA fraction integrity was verified by gel electrophoresis. The RNA solutions were kept at $-80{ }^{\circ} \mathrm{C}$ until further procedures.

Messenger RNA (mRNA) levels were measured by double-stranded DNA dye-based realtime PCR. One microgram of total renal RNA was reverse-transcribed with random hexamer primers by the High-Capacity cDNA Archive Kit (Applied Biosystems) according to the manufacturer's protocol. The quantitative real-time PCR reaction was performed with SensiFAST ${ }^{\mathrm{TM}}$ SYBR ${ }^{\circledR}$ No-ROX Kit (Bioline Reagents Limited, London, UK), according to the manufacturer's protocol, by the Bio-Rad C1000 ${ }^{\mathrm{TM}}$ Thermal Cycler with CFX96 ${ }^{\mathrm{TM}}$ Optics Module real-time PCR system (Bio-Rad Laboratories, Inc., Hercules, CA, USA). Primer annealing was set to $60{ }^{\circ} \mathrm{C}$. Primers (Table 1) were designed by NCBI/Primer-BLAST online software and synthesized by Integrated DNA Technologies (Integrated DNA Technologies, Inc., Coralville, IA, USA). All measurements were done in duplicates. 18S rDNA was used as endogenous reference. The mRNA expressions were calculated with the relative quantification $(\Delta \Delta \mathrm{Cq})$ method, and the efficiency of the quantitative PCR reaction was verified with standard curves.

Table 1 Sequences of primers used for measuring the expression of target genes by qPCR

\begin{tabular}{lll}
\hline Target & Forward primer & Reverse primer \\
\hline Fn1 & CAGACCTACCCAGGCACAAC & CAGCGACCCGTAGAGGTTTT \\
Kim-1 & AAACCAGAGATTCCCACACG & GTCGTGGGTCTTCCTGTAGC \\
Pcna & GCACGTATATGCCGAGACCTT & ACGTTAGGTGAACAGGCTCAT \\
p21 & CTGTCTTGCACTCTGGTGTCT & CTTGCAGAAGACCAATCTGCG \\
Igf2 & GACACGCTTCAGTTTGTCTGTT & AAGCAGCACTCTTCCACGA \\
Igf2r & AAGGACAGGCTCGTTCTGAC & AGTTGGACTTGGCAGTGAGT \\
p16 & CGAACTCGAGGAGAGCCATC & TACGTGAACGTTGCCCATCA \\
p27 & TTCGACGCCAGACGTAAACA & TGCGCAATGCTACATCCAATG \\
\hline Abs & CCAGAATGAGGATCCCAGAA & ACCACCTGAAACATGCAACA \\
\hline
\end{tabular}

Abbreviations: Fn1, fibronectin; Kim-1, kidney injury molecule-1; Pcna, proliferating cell nuclear antigen; p21 also p21 Cipl, cyclin-dependent kinase inhibitor 1; Igf2, insulin-like growth factor receptor 2; Igf $2 r$, insulin-like growth factor-2 receptor; $p 16$ also p16 $6^{I N K 4 a}$, cyclin-dependent kinase inhibitor 2A; p27 also p27Kip1, cyclin-dependent kinase inhibitor 1B; 18S ribosomal RNA 
LncRNA profiling

The lncRNA profile of 5 control and 5 IRI kidneys from both age groups was analyzed with the mouse LncRNA Profiler qPCR Array Kit (catalog Nr.: RA930A-1, System Biosciences, Palo Alto, CA, USA), following the description of the manufacturer. Briefly, 1.5- $\mu$ g total RNA per sample was polyA tailed. Next, dT adapters were annealed to the polyA tailed templates and reverse transcribed into cDNA with random primers. Real-time PCR was performed using Maxima $^{\mathrm{TM}}$ SYBR Green qPCR Master Mix (Thermo Fisher Scientific). The assay contained primers for 90 different lncRNAs and 5 additional reference genes were tested. The specificity of the reaction was verified with melting curve analysis. The lncRNA expressions were calculated with the relative quantification $(\Delta \Delta \mathrm{Cq})$ method.

Data were analyzed using the Ingenuity Pathway Analysis (IPA) software (Qiagen Inc., Hilden, Germany, https://www.qiagenbioinformatics.com/ products/ingenuity-pathway-analysis). Nineteen out of the 90 target lncRNAs of the IncRNA Profiler qPCR Array Kit (Supplementary Table 1) were not registered in the IPA knowledgebase. Thus, the following significantly changed lncRNAs could not be included in the IPA functional context mapping studies: Y RNAs, RepA transcript, linc1242, linc1633, and linc-1610-(med) due to lack of identification for corresponding human genes.

\section{Statistics}

Results are presented as mean \pm standard error of the mean (SEM) unless otherwise indicated. Logarithmic transformation was performed if normality test indicated inhomogeneity of variances. Continuous variables were analyzed using either one-way or two-way analysis of variance (ANOVA), followed by Tukey's multiple comparisons test. The null-hypothesis was rejected if the $p$ value reached statistical significance $(* p<0.05, \quad * * p<0.01$, $* * * p<0.001, \quad * * * * p<0.0001)$. LncRNAs were regarded as significantly changed when the age and/ or the ischemia effect had a significance level of $p<0.05$ as determined by two-way ANOVA.

\section{Results}

Renal parameters altered by aging in the control kidney

Mild morphological deteriorations such as tubule dilation and tubular cell necrosis and apoptosis were detected on HE-stained control kidney slides of old mice (Fig. 1A, B, and I). Tubule regeneration on HE-stained kidney slides was similar in the two age groups (Fig. 1J). There was no visible fibrosis in Masson's trichrome-stained control kidney slides of old and adult mice (Fig. 1E, F, and $\mathrm{K}$ ). The base-line urinary excretion of Lcn-2 was significantly higher in the old group (Fig. 1L); however, base-line plasma urea concentrations were not different in adult and old mice (Fig. 1M). Old age increased the renal mRNA expression of fibronectin (Fn1, Fig. 1N), kidney injury molecule-1 (Kim-1, Fig. 1O), p21 (Fig. 1P), and p16 (Fig. 1Q) but not of proliferating cell nuclear antigen (Pcna, Fig. 1R) and p27 (S).

Adult (age: 10 months) and old (age: 26-30 months) mice subjected to unilateral renal ischemia-reperfusion injury (IRI). Contralateral right kidneys served as controls (CTR). Representative pictures of hematoxylin-eosin (HE) (A-D) and Masson's trichrome (E-H)-stained kidney Sects. (40×magnification). Tubular injury (I) and tubule regeneration $(\mathrm{J})$ scores based on the hematoxylin-eosin-stained kidney sections. Fibrosis score (K) based on the Masson's trichrome-stained sections. Urinary Lcn-2 excretion (L) and plasma urea concentrations (M) 1 day before and 7 days after IRI. Renal Fn1 (N), Kim-1 (O), p21 (P), p16 (Q), Pcna (R), and p27 (S) mRNA expression 7 days after IRI. Two-way ANOVA; ns, not significant; $* p<0.05$, **p $p<0.01$, $* * * p<0.001, * * * * p<0.0001$.

Renal parameters altered by IRI

Twenty-minute renal ischemia and 7-day reperfusion led to pronounced signs of tubular injury, regeneration, and consequent fibrosis with functional impairment in both age groups. Ischemia induced tubule dilation with casts, firm tubule necrosis, and moderate apoptosis as assessed in HE-stained kidney sections (Fig. 1C,D, and I). Tubule regeneration on HE-stained kidney slides increased after IRI (Fig. 1J). Significant fibrosis was detected on Masson's trichrome-stained slides 
Hematoxylin-eosin
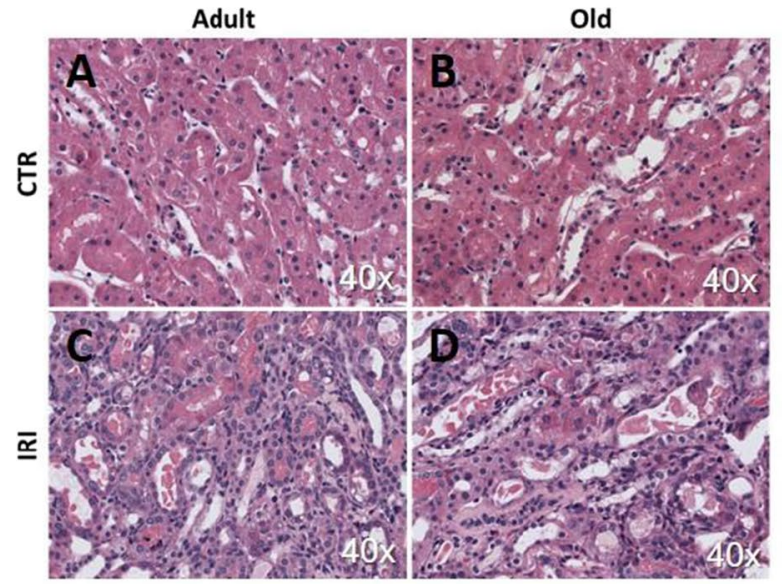

Masson's trichrome
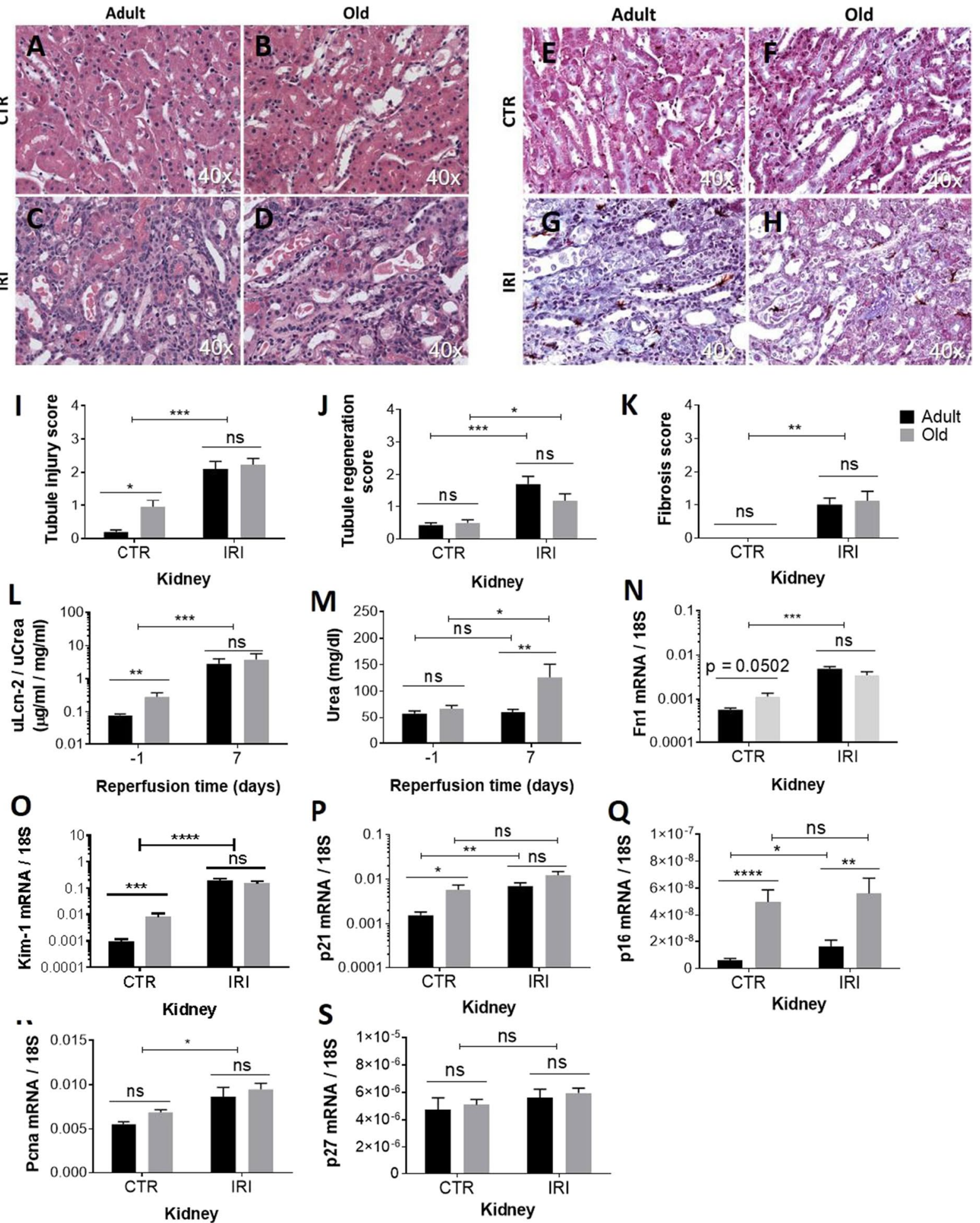
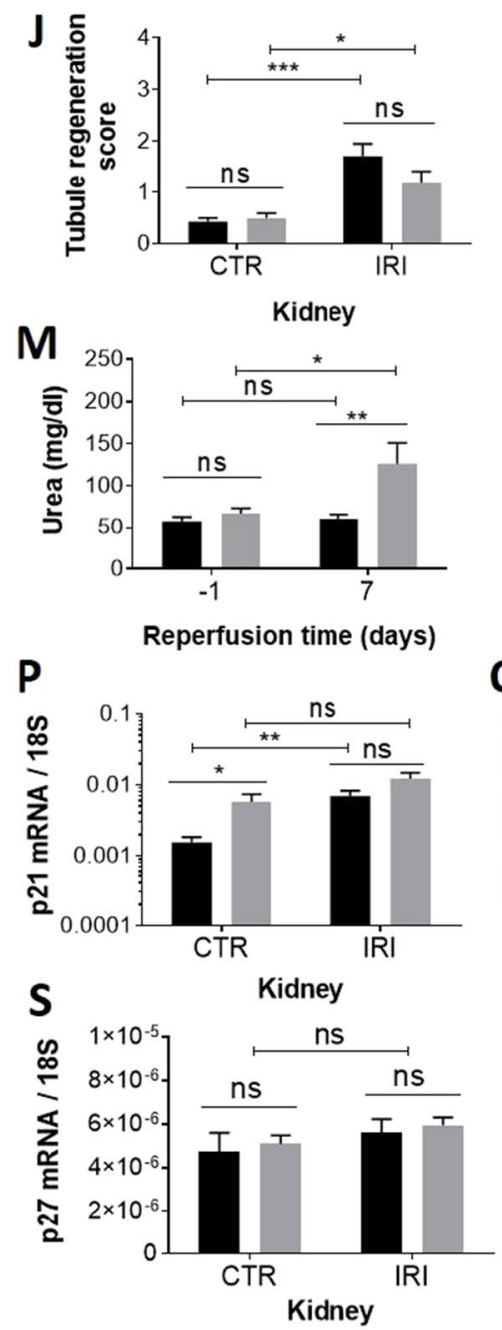
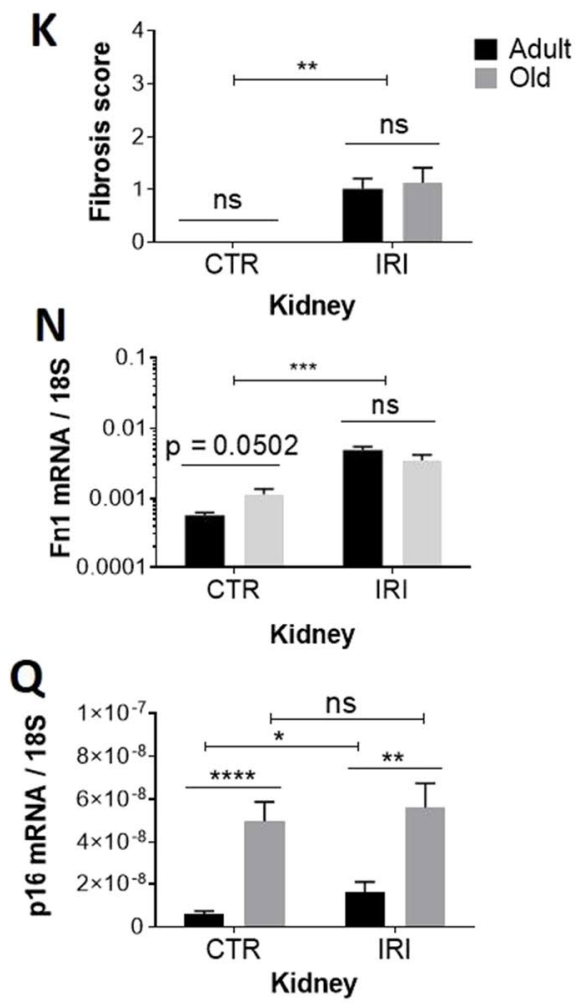

Fig. 1 The effects of aging and ischemia on renal morphology and function 
Fig. 2 LncRNA profiling in the kidneys. Adult (age: 10 months) and old (age: 26-30 months) mice subjected to unilateral renal ischemia-reperfusion injury (IRI). Contralateral right kidneys served as controls (CTR). (A) Heat map of significantly changed lncRNAs (Rm, right kidney from adult mice; Ro, right kidney from old mice; Lm, left kidney from adult mice; Lo, left kidney from old mice). The effects of age $(\mathrm{B}, \mathrm{C})$ in the control (B) and in the IRI (C) kidneys. The effects of IRI $(D, E)$ in the kidneys of adult (D) and of old (E) mice. (B-E): horizontal lines mark $p=0.05$; vertical lines mark $F C=2 x$. One-way ANOVA

A
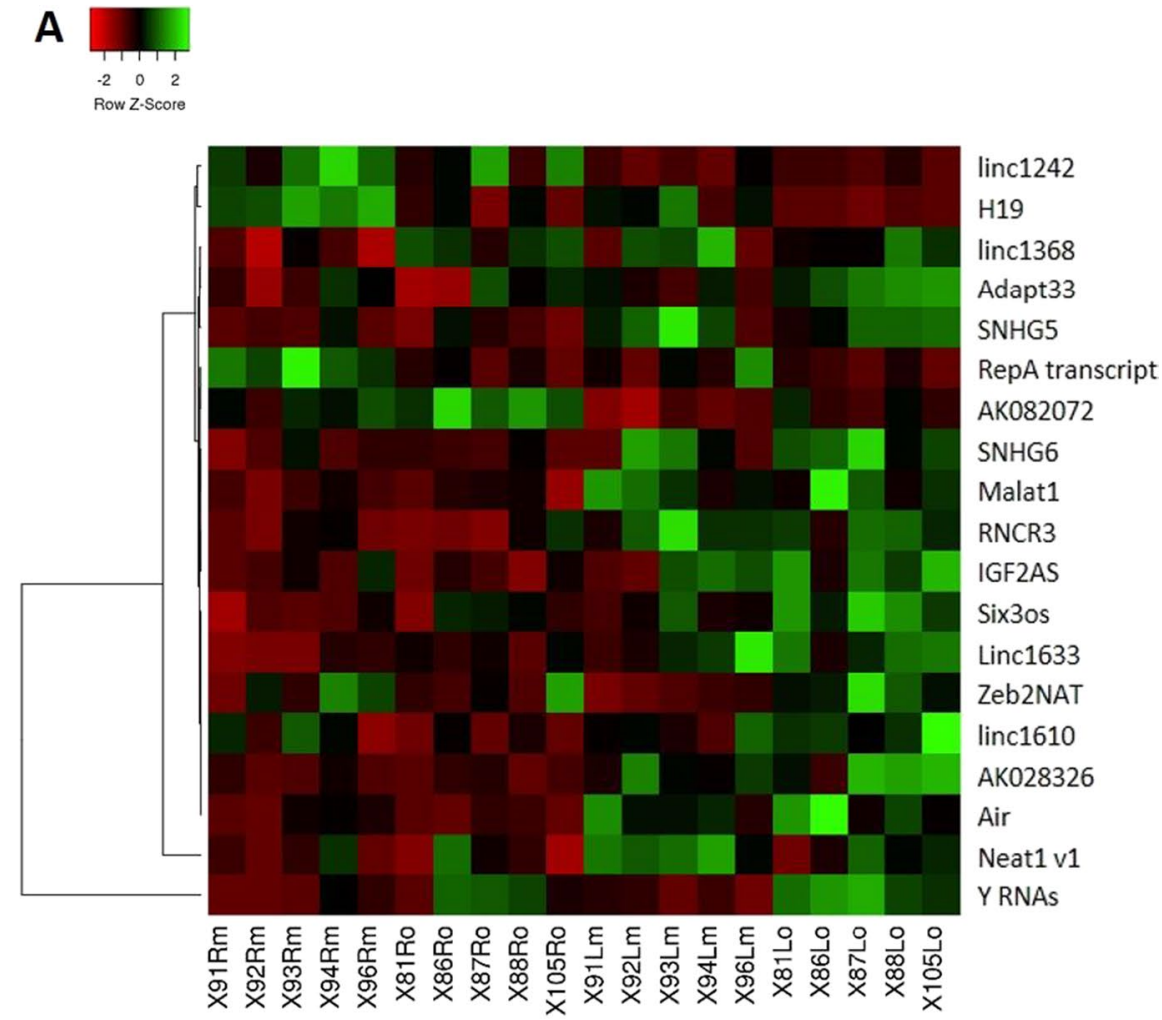

B

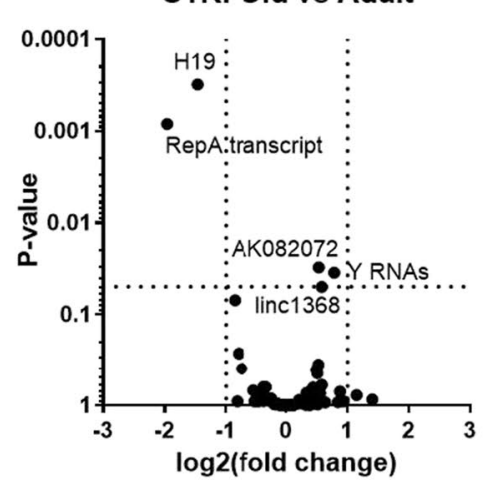

D

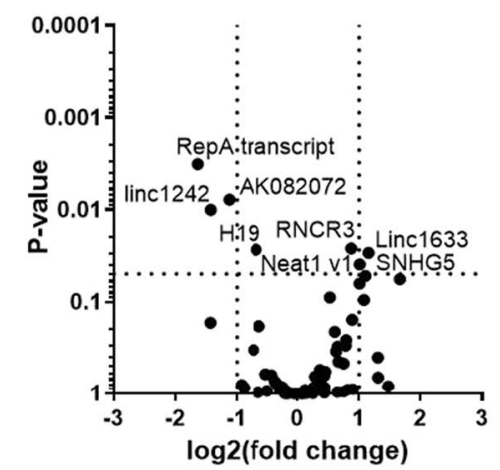

C

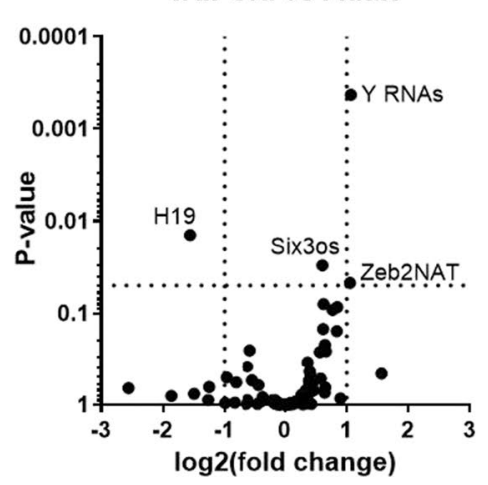

E

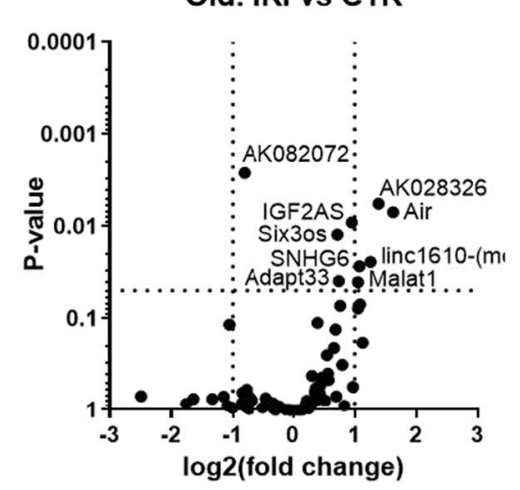


Upregulated by aging

A

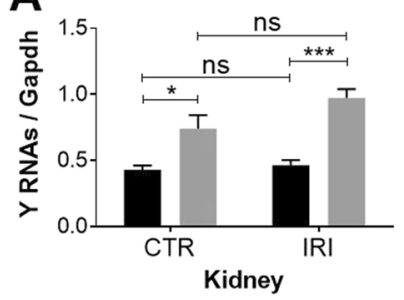

Downregulated by both aging and IRI

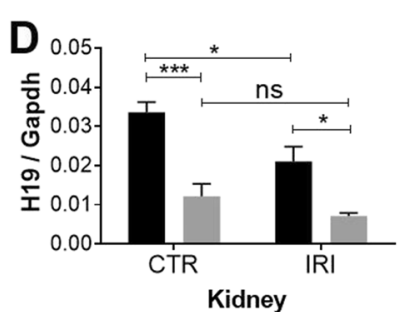

G
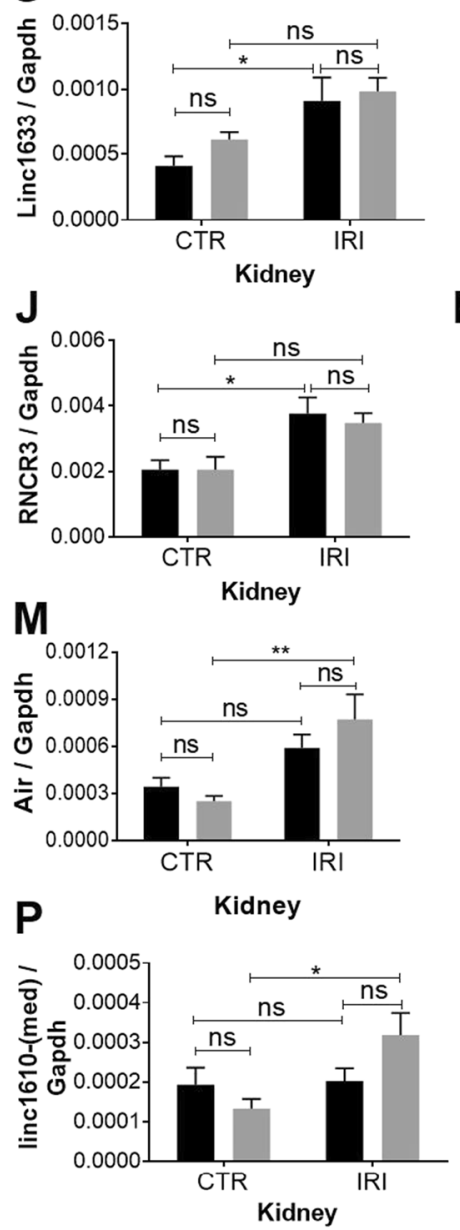

Upregulated by both

B aging and IRI

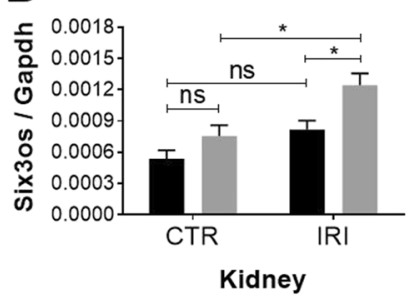

E

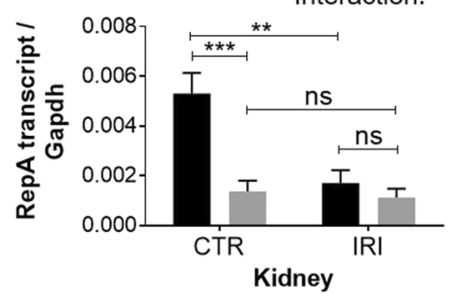

Upregulated by IRI

$\mathrm{H}$

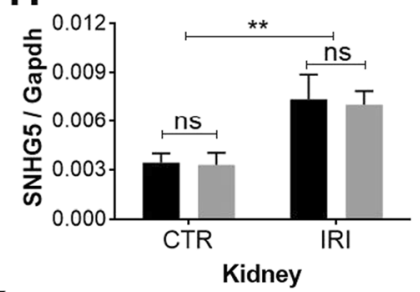

K
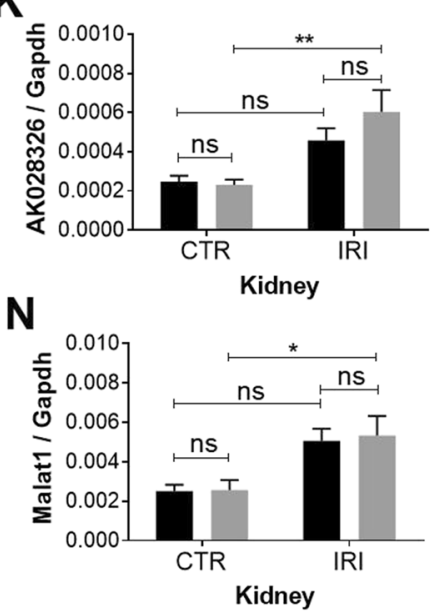

Q

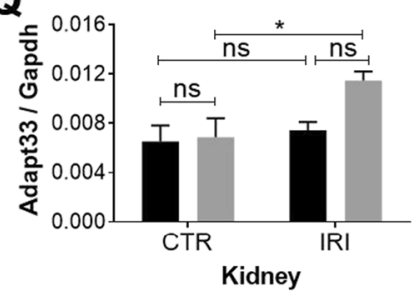

Inversely regulated by

C aging (up) and IRI (down)

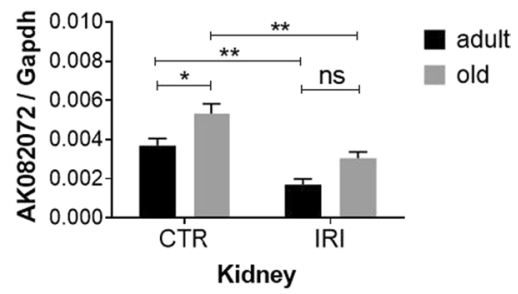

Downregulated by IRI

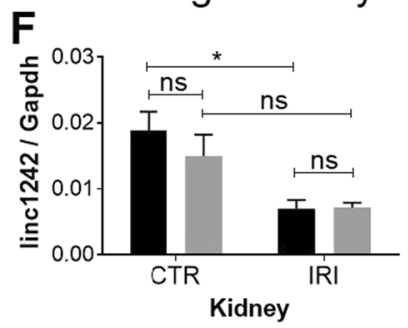

I

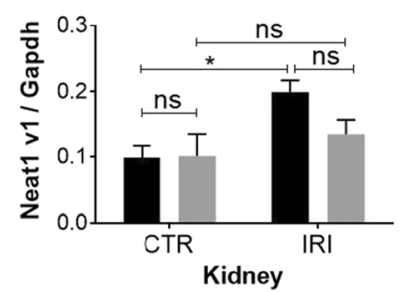

$\mathbf{L}$

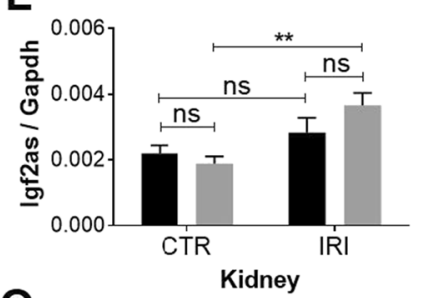

0

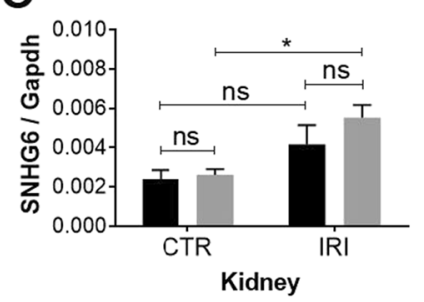


4Fig. 3 Renal expression of lncRNAs altered by IRI and/or aging. (A) Y RNAs, (B) Six3os, (C) AK082072, (D) H19, (E) RepA transcript, (F) linc1242, (G) Linc1633, (H) SNHG5, (I) Neat1 v1, (J) RNCR3, (K) AK028326 (Miat), (L) Igf2as, (M) Air, (N) Malat1, (O) SNHG6, (P) linc1610-(med), (Q) Adapt33. Adult (age: 10 months) Adapt33 and old (age: 26-30 months) mice subjected to unilateral renal ischemiareperfusion injury (IRI). Contralateral right kidneys served as controls (CTR). LncRNA expression was normalized to GAPDH. Two-way ANOVA; ns, not significant; $* p<0.05$, $* * p<0.01, * * * p<0.001$ (Tukey's multiple comparisons test)

following IRI (Fig. 1G, H, and K). There was a strong elevation in urinary Lcn-2 excretion after IRI (Fig. 1L). The mRNA expression of Fn1 (Fig. 1N), Kim-1 (Fig. 1O), p21 (Fig. 1P), and Pcna (Fig. 1R) increased after IRI. All these parameters were similar in adult and old mice. Furthermore, 7 days after ischemia, plasma urea levels were elevated only in the old group, and not in the adult group (Fig. 1M). At the same time, p16 increased only in the adult group, while it was not further elevated in old mice after IRI (Fig. 1Q).

Renal lncRNA profile of adult and old mice prior to and after renal IRI

The qPCR array included 90 lncRNAs. We excluded 6 lncRNAs due to the lack of amplification, and further
3 lncRNAs because of unspecific reaction products, leaving 81 valid lncRNAs for further analysis. Gapdh varied the least among the reference genes included on the qPCR array; thus, IncRNA expressions were normalized to Gapdh. Figure 2 shows the heatmap of altered lncRNAs and volcano plots of pairwise comparisons. Altogether, 17 lncRNAs changed significantly (two-way ANOVA, $p<0.05$, Fig. 3, Table 2). In old non-ischemic (CTR) kidneys compared to adult kidneys (Fig. 2B), H19 (Fig. 3D) and RepA transcript (Fig. 3E) were downregulated $(\mathrm{FC}>2)$ and Y RNAs (Fig. 3A) and AK082072 (Fig. 3C) were upregulated significantly but with $\mathrm{FC}<2$. Furthermore, H19 (down) and Y RNAs (up) were similarly regulated both by age (Fig. 2B) and by IRI (Fig. 2C). On the other hand, in adult mice, IRI led to the downregulation of RepA transcript, Linc1242 (Fig. 3F), and AK082072, and to the upregulation of Linc1633 (Fig. 3G), SNHG5 (Fig. 3H), Neat1 v1 (Fig. 3I) (FC $>2$ ), and RNCR3 (Fig. 3J, FC > 1.5) (Fig. 2D). AK082072 was downregulated by ischemia in both adult (Fig. 2D) and old (Fig. 2E) kidneys. This was the only downregulated lncRNA by ischemia in old mice. However, Six3os (Fig. 3B), AK028326 (Miat) (Fig. 3K), Igf2as (Fig. 3L), Air (Fig. 3M), Malat1 (Fig. 3N), SNHG6 (Fig. 3O), linc1610 (Fig. 3P), and Adapt33 (Fig. 3Q) were all upregulated $(\mathrm{FC}>1.5)$

Table 2 Summary of lncRNA changes

\begin{tabular}{|c|c|c|c|c|c|}
\hline & lncRNA & CTR:old vs CTR:adult & IRI:old vs IRI:adult & IRI:adult vs. CTR:adult & IRI:old vs. CTR:old \\
\hline 1 & Y RNAs & Upregulated & Upregulated & & \\
\hline 2 & Six3os & & Upregulated & & Upregulated \\
\hline 3 & AK082072 & Upregulated & & Downregulated & Downregulated \\
\hline 4 & H19 & Downregulated & Downregulated & Downregulated & \\
\hline 5 & RepA transcript & Downregulated & & Downregulated & \\
\hline 6 & Linc1242 & & & Downregulated & \\
\hline 7 & Linc1633 & & & Upregulated & \\
\hline 8 & SNHG5 & & & Upregulated & \\
\hline 9 & Neat1 v1 & & & Upregulated & \\
\hline 10 & RNCR3 & & & Upregulated & \\
\hline 11 & AK028326 (Miat) & & & & Upregulated \\
\hline 12 & Igf2as & & & & Upregulated \\
\hline 13 & Air & & & & Upregulated \\
\hline 14 & Malat1 & & & & Upregulated \\
\hline 15 & SNHG6 & & & & Upregulated \\
\hline 16 & linc1610-(med) & & & & Upregulated \\
\hline 17 & Adapt33 & & & & Upregulated \\
\hline
\end{tabular}




\section{CTRL kidney in old vs. mature mice}

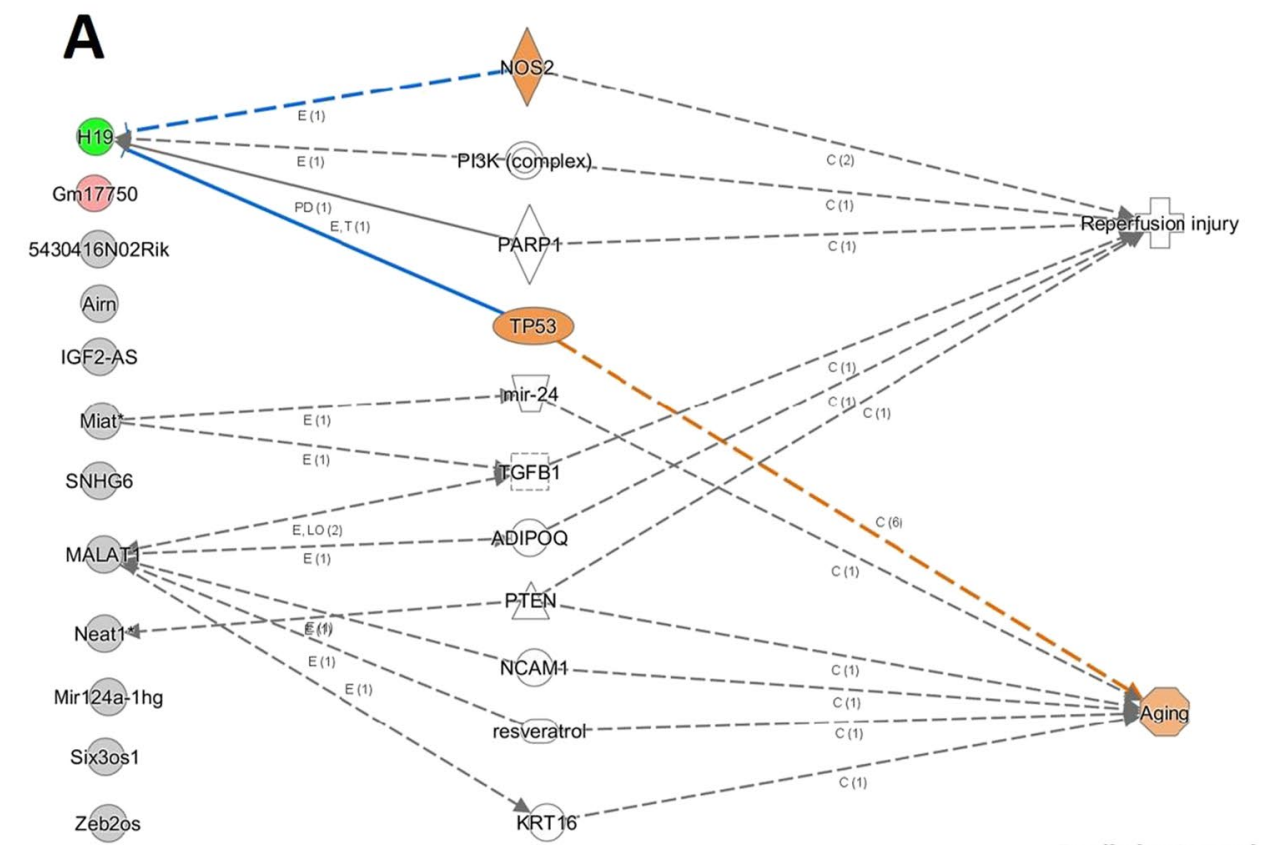

O 2000-2020 QIA GEN. All rights reserved.
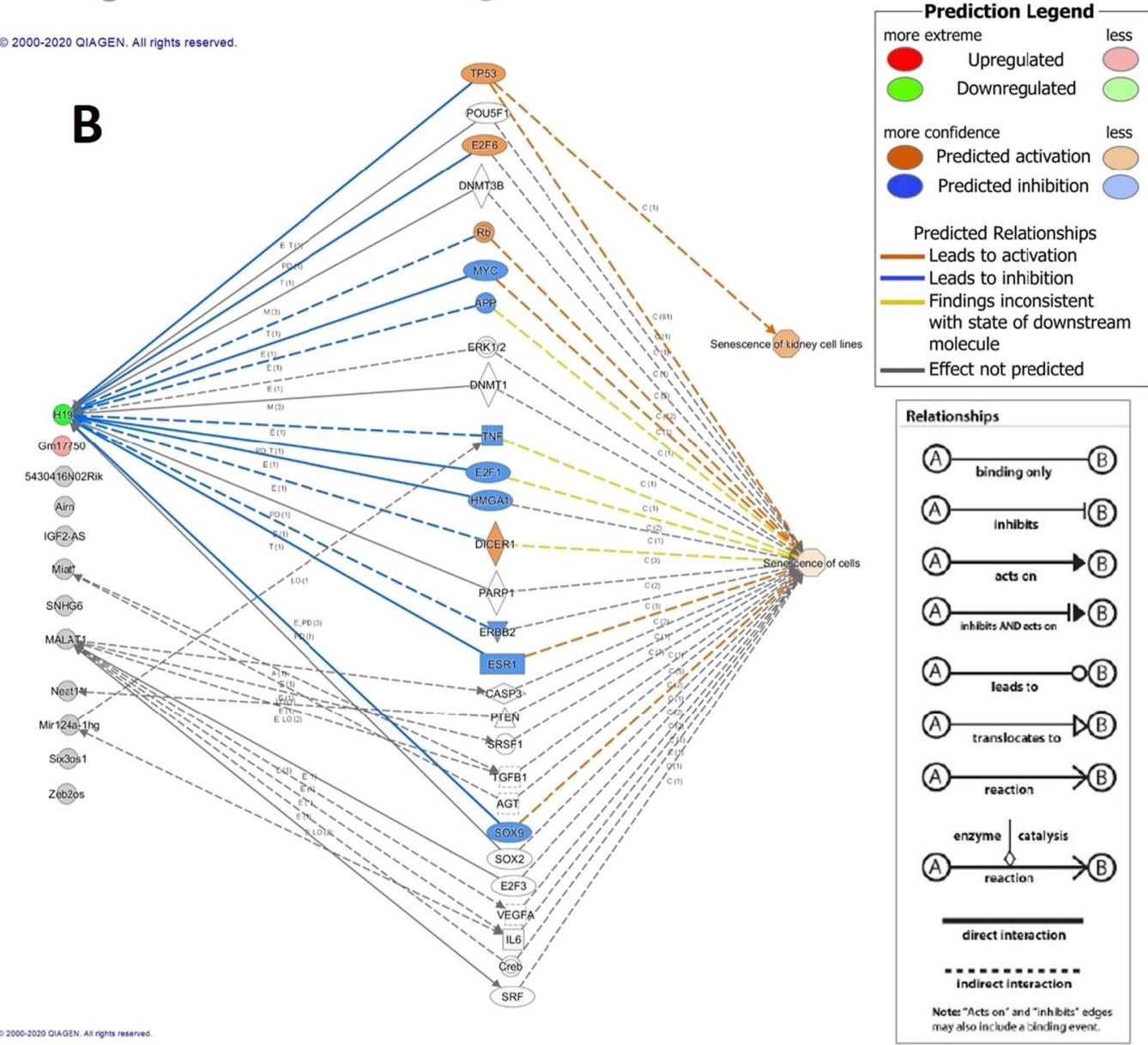
4Fig. 4 IPA analysis supports the potential functional connection between significantly influenced lncRNAs and aging (A) and senescence (B) in control (non-ischemic) kidneys. miR-124a-1gh: Rncr3, 5430416N02Rik: Adapt33, Gm17750: AK082072

by IRI in old mice. H19 was downregulated both by age (Fig. 2B) and by IRI in both adult and old mice (Fig. 2C, D), whereas RepA transcript was downregulated both by age (Fig. 2B) and by IRI only in adult mice (Fig. 2D).

Ingenuity Pathway Analysis

An investigation done by Ingenuity Pathway Analysis (IPA) software demonstrated that H19 downregulation was linked to aging through p53/TP53 (Fig. 4A). IPA associated senescence with H19 through several pathways including p53 in old (non-ischemic) kidneys (Fig. 4B).

The IPA analysis predicted a different activation pattern in the network of functional connections between IncRNAs and senescence when adult or old mice were investigated. In adult mice, downregulation of H19 was linked to senescence of kidney cells. IPA predicted that IRI promoted senescence through the upregulation of Miat/AK028326 and Malat1 in old mice (Fig. 5).

\section{Discussion}

In the present study, we detected renal tubular dysfunction in normal kidneys of aged mice based on mild tubular dilation, tubular cell death, upregulation of Kim-1 mRNA, and urinary Lcn-2 excretion. Kim-1 and Lcn-2 are proximal and distal tubular damage markers, respectively. Senescence was also evident in the kidneys of old mice (increased renal p16 and p21 mRNA). Although Fn1 gene expression was elevated too, fibrotic deposition was similar in old and adult mice. Despite the above signs of renal aging, renal function was not reduced in old mice as their baseline plasma urea concentration was not higher than in adult mice. Following unilateral ischemia-reperfusion injury (IRI), plasma urea was not elevated in adult mice as the contralateral kidney compensated for the loss in functional nephrons. However, plasma urea significantly increased in aged mice after IRI, most probably due to lower renal reserve that occurs during aging [2, 4]. Most other functional parameters were similar after IRI in the two age groups. Unexpectedly, the senescence marker p27 mRNA was similar in the kidneys of adult and old mice, and did not change after IRI, although renal p27 protein expression was shown to increase in mice after 7 days of unilateral ureteral occlusion [28] and in diabetes [29]. However, p27 is mainly regulated at the post-transcriptional level through the regulation of its degradation [30].

Ischemia had a more profound effect on expression of lncRNAs than age. We observed the strongest effect in the kidneys of old mice after IRI, as 8 lncRNAs (AK08326, Air, IGF2AS, Six3os, SNHG6, linc1610, Adapt33, and Malat1) were upregulated, while only 4 lncRNAs were upregulated by ischemia in adult mice. The lncRNA profile in postischemic kidneys of old mice is unique, as no previous studies have investigated the complex lncRNA response to renal IRI in old age. H19 and RepA transcripts were downregulated by both age and IRI, whereas, AK082072 was downregulated by IRI in both adult and old mice.

Ingenuity Pathway Analysis (IPA) demonstrated that H19 downregulation was linked to aging through p53/TP53. There is a counterregulatory relationship between p53 and H19, as p53 represses H19 expression and H19 suppresses p53 activation [31]. This inverse regulation was observed in several pathological conditions [32, 33]. Also, p53 is known to be dysregulated during aging [34]. Enhanced p53 activity leads to premature aging in mice [35]. Furthermore, p53 induces cellular senescence by activating p21 [36].

Besides old age, IRI also suppressed H19 and upregulated p16 and p21 expression in adult mice. Suppression of H19 correlated with the upregulation of p16 [37] and p21 [37, 38] in other studies. H19 was found to be upregulated and promote renal fibrosis in mice after unilateral ureteral obstruction [39]. However, H19 seems to be differently regulated by IRI and unilateral ureteral obstruction as it was downregulated in the IRI-injured kidneys.

In accordance with our results, both aging and IRI were accompanied by elevated renal p16 and p21 expression in mice [40, 41]. However, p16 and p21 were significantly upregulated by IRI only in adult 

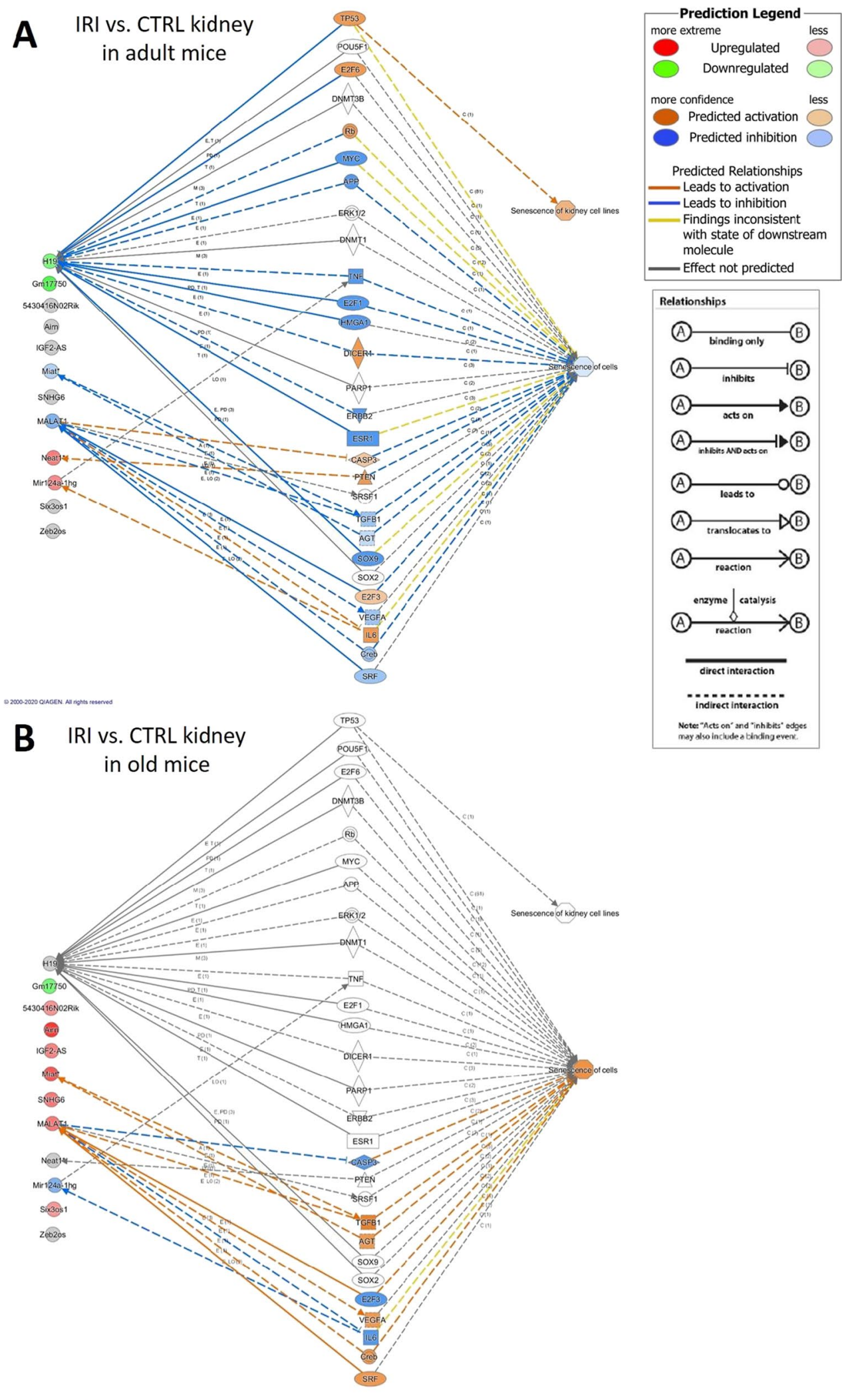

may also include a bindingevent. 
4Fig. 5 IPA analysis supports the potential functional connection between significantly influenced lncRNAs and senescence in injured vs. control kidneys in adult (A) and old (B) mice. miR-124a-1gh: Rncr3, 5430416N02Rik: Adapt33, Gm17750: AK082072

mice. Enhanced expression of p21 was found to be protective in the early phases of renal IRI [42, 43]. Also, fibrosis was exacerbated after unilateral ureteral obstruction in p21-deficient mice [44]. Thus, the lack of IRI effect on p21 in old mice might worsen kidney injury.

Besides H19 [37, 38], and SNHG6 [45-47], Miat [48] and Malat1 [49-52] correlated with the regulation of the senescence-regulatory tumor suppressor gene p21. Miat was also associated with p16 [48, 53]. LncRNA SNHG6 was demonstrated to repress p21 [45-47]. Contrary to p21, IncRNA SNHG6 was significantly upregulated by IRI only in old mice. Therefore, we hypothesize that in aged mice, the lack of IRI-induced p21 induction can be related to the upregulated SNHG6 expression. Furthermore, SNHG6 was found to activate the TGF- $\beta /$ Smad signaling pathway $[54,55]$ that has a central role in renal fibrogenesis [56]. Although on day 7 there was no difference in the extent of renal fibrosis between the two age groups, upregulation of SNHG6 in the kidneys of old mice may enhance fibrosis on the long term.

AK028326 (also known as RNCR2 or Gomafu), generally called myocardial infarction associated transcript (Miat), was described as a pro-fibrotic and pro-apoptotic lncRNA following myocardial ischemia $[57,58]$. Furthermore, Miat was found to upregulate TGF- $\beta$ expression (59). Miat was also associated with kidney fibrosis [60] and high glucose-induced renal tubular epithelial injury [61]. Here we show for the first time that Miat was upregulated by renal IRI. Obviously, enhanced expression of Miat may contribute to the development and progression of the IRIinduced renal fibrosis.

In accordance with previous findings [23, 62, 63], Malat1 was upregulated after renal IRI, although it had a minor impact on the IRI-induced renal damage [23]. Contrary to our results in the kidney, Malat1 and p21 were found to be inversely regulated in various carcinomas [49-52]. Malat1 is also known to suppress p53 [49], another senescence-regulatory tumor suppressor gene. Further studies are needed to determine how Malat1 and p21 interact in the setting of renal IRI.

Renal expression of RepA was downregulated by both IRI and aging. RepA has a role in X-chromosome inactivation [64]. It is one of the lncRNAs that bind to the histone methyltransferase polycomb repressive complex 2 (PRC2) [65]. Besides X-inactivation, $\mathrm{PRC} 2$ also plays a role in the DNA damage response, DNA replication, and the regulation of senescence. Deregulation of PRC2 has been identified in malignancies, and also in aged or stressed cells [66].

Igf2as was upregulated by IRI in the kidneys of old mice. Igf2as inhibition was found to be protective in different disease models by inducing cardiac angiogenesis in type 2 diabetes [67] and neuronal growth in neurotoxicity [68]. Also, Igf2as was downregulated in several types of cancers and suggested to act as a tumor suppressor [69]. Taken together, enhanced Igf2as expression seems to inhibit cell growth. In most cases, it was proposed to act by regulating the expression of insulin-like growth factor 2 (Igf2) [67-69]. It was also reported that Igf2as encoded for a protein [70, 71].

Renal expression of Air was upregulated by IRI. LncRNA Air silences insulin-like growth factor-2 receptor (Igf2r) and organic cation transporters 2 and 3 (Slc22a2/Oct2 and Slc22a3/Oct3) [72]. Air also controls the expression of Slc22a2/Slc22a3 and Igf2r in a different way [72]. Renal expression of Slc22a2 was downregulated by IRI [73]. Furthermore, enhanced expression of Air was correlated with the suppression of $\mathrm{Wnt} / \beta$-catenin, mTOR, and PI3K signaling [74]. $\beta$-catenin, mTOR, and PI3K were all found to be downregulated in the kidney after IRI [75, 76]. Therefore, upregulation of Air fits into the observed gene expression changes caused by renal IRI.

Y RNAs and Zeb2NAT were the only lncRNAs that were affected by aging only. Renal expression of Y RNAs was upregulated in old mice in both kidneys. Y RNAs are highly expressed in the kidneys of mice [77] and were shown to be upregulated in various cancers [78]. Y RNAs have been associated with numerous cellular processes involved in aging (e.g., cell proliferation [78], DNA replication, stress responses, RNA quality control [79], inflammation and apoptosis [80]) but their role in aging has not yet been exploited. Zeb2NAT expression was 
significantly elevated in old IRI kidneys compared to adult IRI kidney. Knockdown of Zeb2NAT was shown to facilitate reprogramming of aged fibroblasts into pluripotent cells [81].

Neat1 was upregulated by IRI in adult mice. Neat1 was upregulated in ischemia-induced AKI in patients [82]. Neat1 was also induced during the progression of renal fibrosis [83].

Renal expression of AK082072 (also called TMEM161B-AS1) was downregulated by IRI and upregulated by aging. AK082072 was found to be expressed primarily in murine brain tissues [84] but its function is unknown.

IRI upregulated Adapt33 in the kidneys of old mice. Adapt33 was described as a stress-inducible IncRNA that was associated with apoptosis [85].

Six3os (Six3 opposite strand) was also upregulated by IRI in the kidneys of old mice. Six 30 s is involved in embryonic brain and retinal development [86] and adult neurogenesis [87]. It regulates the expression of Six 3 and its target genes [88]. Its role in other organs or in aging has not yet been studied.

In our study, IRI upregulated renal expression of RNCR3 (Retinal non-coding RNA3, also known as LINC00599). To date RNCR3 has been found to play a role in diabetic retinopathy [89], atherosclerosis-related vascular dysfunction [90], glioma [91], and prostate cancer [92].

IRI also upregulated renal expression of SNHG5 (Small Nucleolar RNA Host Gene 5). SNHG5 was shown to act as a sponge of miR-154-5p, which silences Pcna mRNA, thereby enhancing Pcna expression [93]. Accordingly, Pcna mRNA was also elevated after IRI.

From the 17 dysregulated lncRNAs, no information is available for Linc1242 (downregulated by IRI), Linc1633, and linc1610-(med) (upregulated by IRI).

One of the strengths of our study is that we used mice aged between 26 and 30 months, which is rare in kidney studies as the age of old mice is 24 months or even less in most studies. This age corresponds to an approximate human age of $70-80$ years [94, 95]. Adult mice (10 months old) served as controls, corresponding to an approximate human age of 30-40 years. It was demonstrated before that age had only minimal impact on the early phases of renal injury after IRI in adult (or middle-aged) mice and rats (up to 12 months of age) [96, 97].

In conclusion, our results indicate that both aging and renal IRI alter the expression of several lncRNAs. As none of the lncRNAs showed an outstanding change, and as the pattern of the altered lncRNAs is quite diversified, it can be hypothesized that lncRNAs have a versatile and complex role in kidney pathophysiology.

Acknowledgements The authors are grateful to Ildikó Virág and Viktória Szabó-Honfi for taking care of the animals.

Funding Open access funding provided by Semmelweis University. This research was funded by the Hungarian Research Fund: OTKA SNN-114619 (PH), ANN-110810 (PH), by the National Research, Development and Innovation Fund of Hungary: NVKP_16-1-2016-0042 (PH), by the Economic Development and Innovation Operative Program Grant: GINOP 2.3.2-15-2016-00048 (PH), by the ÚNKP-17-4-I-SE-79 New National Excellence Program of the Ministry of Human Capacities (TK), and by the EFOP-3.6.3-VEKOP-16-2017-00009 grant $(\mathrm{PH})$. Péter Hamar is a recipient of the Kispál Gyula startup grant (300021) of the University of Pécs. Pál Tod was partially supported from the Kispál Gyula grant (300021) of the University of Pécs.

Open Access This article is licensed under a Creative Commons Attribution 4.0 International License, which permits use, sharing, adaptation, distribution and reproduction in any medium or format, as long as you give appropriate credit to the original author(s) and the source, provide a link to the Creative Commons licence, and indicate if changes were made. The images or other third party material in this article are included in the article's Creative Commons licence, unless indicated otherwise in a credit line to the material. If material is not included in the article's Creative Commons licence and your intended use is not permitted by statutory regulation or exceeds the permitted use, you will need to obtain permission directly from the copyright holder. To view a copy of this licence, visit http://creativecommons.org/licenses/by/4.0/.

\section{References}

1. Hoste EAJ, Kellum JA, Selby NM, Zarbock A, Palevsky PM, Bagshaw SM, et al. Global epidemiology and outcomes of acute kidney injury. Nat Rev Nephrol. 2018;14(10):607-25.

2. Rosner MH. Acute kidney injury in the elderly. Clin Geriatr Med. 2013;29(3):565-78.

3. Schmitt R, Coca S, Kanbay M, Tinetti ME, Cantley LG, Parikh CR. Recovery of kidney function after acute kidney injury in the elderly: a systematic review and metaanalysis. Am J Kidney Dis. 2008;52(2):262-71.

4. O'Sullivan ED, Hughes J, Ferenbach DA. Renal aging: causes and consequences. J Am Soc Nephrol. 2017;28(2):407-20. 
5. Kusaka J, Koga H, Hagiwara S, Hasegawa A, Kudo K, Noguchi T. Age-dependent responses to renal ischemiareperfusion injury. J Surg Res. 2012;172(1):153-8.

6. Xu X, Fan M, He X, Liu J, Qin J, Ye J. Aging aggravates long-term renal ischemia-reperfusion injury in a rat model. J Surg Res. 2014;187(1):289-96.

7. Zhang Y, Li Q, Liu D, Huang Q, Cai G, Cui S, et al. GDF11 improves tubular regeneration after acute kidney injury in elderly mice. Sci Rep. 2016;6:34624.

8. Shimizu MH, Araujo M, Borges SM, de Tolosa EM, Seguro AC. Influence of age and vitamin $\mathrm{E}$ on post-ischemic acute renal failure. Exp Gerontol. 2004;39(5):825-30.

9. Gonsalez SR, Cortes AL, Silva RCD, Lowe J, Prieto MC, Silva Lara LD. Acute kidney injury overview: from basic findings to new prevention and therapy strategies. Pharmacol Ther. 2019;200:1-12.

10. Wu R, Su Y, Wu H, Dai Y, Zhao M, Lu Q. Characters, functions and clinical perspectives of long non-coding RNAs. Mol Genet Genomics. 2016;291(3):1013-33.

11. Kour S, Rath PC. Long noncoding RNAs in aging and age-related diseases. Ageing Res Rev. 2016;26:1-21.

12. Ignarski M, Islam R, Muller RU. Long non-coding RNAs in kidney disease. Int J Mol Sci. 2019;20(13):3276.

13. Moghaddas Sani H, Hejazian M, Hosseinian Khatibi SM, Ardalan M, Zununi VS. Long non-coding RNAs: an essential emerging field in kidney pathogenesis. Biomed Pharmacother. 2018;99:755-65.

14. Sun J, Zhang S, Shi B, Zheng D, Shi J. Transcriptome identified lncRNAs associated with renal fibrosis in UUO rat model. Front Physiol. 2017;8:658.

15. Zhou Q, Chung AC, Huang XR, Dong Y, Yu X, Lan HY. Identification of novel long noncoding RNAs associated with TGF-beta/Smad3-mediated renal inflammation and fibrosis by RNA sequencing. Am J Pathol. 2014;184(2):409-17.

16. Zhou Q, Huang XR, Yu J, Yu X, Lan HY. Long noncoding RNA Arid2-IR is a novel therapeutic target for renal inflammation. Mol Ther. 2015;23(6):1034-43.

17. Feng M, Tang PM, Huang XR, Sun SF, You YK, Xiao J, et al. TGF-beta mediates renal fibrosis via the Smad3-Erbb4-IR long noncoding RNA axis. Mol Ther. 2018;26(1):148-61.

18. Wang P, Luo ML, Song E, Zhou Z, Ma T, Wang J, et al. Long noncoding RNA lnc-TSI inhibits renal fibrogenesis by negatively regulating the TGF-beta/Smad3 pathway. Sci Transl Med. 2018;10(462):eaat2039.

19. Yu TM, Palanisamy K, Sun KT, Day YJ, Shu KH, Wang IK, et al. RANTES mediates kidney ischemia reperfusion injury through a possible role of HIF-1alpha and LncRNA PRINS. Sci Rep. 2016;6:18424.

20. Lin J, Zhang X, Xue C, Zhang H, Shashaty MG, Gosai SJ, et al. The long noncoding RNA landscape in hypoxic and inflammatory renal epithelial injury. Am J Physiol Renal Physiol. 2015;309(11):F901-13.

21. Jin L, Song Q, Zhang W, Geng B, Cai J. Roles of long noncoding RNAs in aging and aging complications. Biochim Biophys Acta Mol Basis Dis. 2019;1865(7):1763-71.

22. Lorenzen JM, Kaucsar T, Schauerte C, Schmitt R, Rong $\mathrm{S}$, Hubner A, et al. MicroRNA-24 antagonism prevents renal ischemia reperfusion injury. J Am Soc Nephrol. 2014;25(12):2717-29.
23. Kolling M, Genschel C, Kaucsar T, Hubner A, Rong S, Schmitt R, et al. Hypoxia-induced long non-coding RNA Malat1 is dispensable for renal ischemia/reperfusioninjury. Sci Rep. 2018;8(1):3438.

24. Kaucsar T, Revesz C, Godo M, Krenacs T, Albert M, Szalay CI, et al. Activation of the miR-17 family and miR21 during murine kidney ischemia-reperfusion injury. Nucleic Acid Ther. 2013;23(5):344-54.

25. Kaucsar T, Godo M, Revesz C, Kovacs M, Mocsai A, Kiss $\mathrm{N}$, et al. Urine/plasma neutrophil gelatinase associated lipocalin ratio is a sensitive and specific marker of subclinical acute kidney injury in mice. PLoS One. 2016;11(1):e0148043.

26. Mishra J, Ma Q, Prada A, Mitsnefes M, Zahedi K, Yang $\mathrm{J}$, et al. Identification of neutrophil gelatinase-associated lipocalin as a novel early urinary biomarker for ischemic renal injury. J Am Soc Nephrol. 2003;14(10):2534-43.

27. Elmore SA, Dixon D, Hailey JR, Harada T, Herbert RA, Maronpot RR, et al. Recommendations from the INHAND Apoptosis/Necrosis Working Group. Toxicol Pathol. 2016;44(2):173-88.

28. Dan Q, Shi Y, Rabani R, Venugopal S, Xiao J, Anwer S, et al. Claudin-2 suppresses GEF-H1, RHOA, and MRTF, thereby impacting proliferation and profibrotic phenotype of tubular cells. J Biol Chem. 2019;294(42):15446-65.

29. Vallon V, Rose M, Gerasimova M, Satriano J, Platt KA, Koepsell H, et al. Knockout of Na-glucose transporter SGLT2 attenuates hyperglycemia and glomerular hyperfiltration but not kidney growth or injury in diabetes mellitus. Am J Physiol Renal Physiol. 2013;304(2):F156-67.

30. Hnit SST, Xie C, Yao M, Holst J, Bensoussan A, De Souza $\mathrm{P}$, et al. p27Kip1 signaling: transcriptional and post-translational regulation. Int $\mathrm{J}$ Biochem Cell Biol. 2015;68:9-14.

31. Raveh E, Matouk IJ, Gilon M, Hochberg A. The H19 long non-coding RNA in cancer initiation, progression and metastasis - a proposed unifying theory. Mol Cancer. 2015; $14: 184$.

32. Wang J, Cao B, Zhao H, Gao Y, Luo Y, Chen Y, et al. Long noncoding RNA H19 prevents neurogenesis in ischemic stroke through p53/Notch1 pathway. Brain Res Bull. 2019;150:111-7.

33. Li Y, Ma HY, Hu XW, Qu YY, Wen X, Zhang Y, et al. LncRNA H19 promotes triple-negative breast cancer cells invasion and metastasis through the p53/TNFAIP8 pathway. Cancer Cell Int. 2020;20:200.

34. Tabibzadeh S. Signaling pathways and effectors of aging. Front Biosci (Landmark Ed). 2021;26:50-96.

35. Tyner SD, Venkatachalam S, Choi J, Jones S, Ghebranious $\mathrm{N}$, Igelmann $\mathrm{H}$, et al. p53 mutant mice that display early ageing-associated phenotypes. Nature. 2002;415(6867):45-53.

36. Rufini A, Tucci P, Celardo I, Melino G. Senescence and aging: the critical roles of p53. Oncogene. 2013;32(43):5129-43.

37. Hofmann P, Sommer J, Theodorou K, Kirchhof L, Fischer A, Li Y, et al. Long non-coding RNA H19 regulates endothelial cell aging via inhibition of STAT3 signalling. Cardiovasc Res. 2019;115(1):230-42.

38. Sajadpoor Z, Amini-Farsani Z, Teimori H, Shamsara M, Sangtarash MH, Ghasemi-Dehkordi P, et al. Valproic 
acid promotes apoptosis and cisplatin sensitivity through downregulation of $\mathrm{H} 19$ noncoding RNA in ovarian A2780 cells. Appl Biochem Biotechnol. 2018;185(4):1132-44.

39. Xie H, Xue JD, Chao F, Jin YF, Fu Q. Long non-coding RNA-H19 antagonism protects against renal fibrosis. Oncotarget. 2016;7(32):51473-81.

40. Johnson AC, Zager RA. Plasma and urinary p21: potential biomarkers of AKI and renal aging. Am J Physiol Renal Physiol. 2018;315(5):F1329-35.

41. Sari FT, Sari FT, Sari FT, Arfian N, Sari DCR. Effect of kidney ischemia/reperfusion injury on proliferation, apoptosis, and cellular senescence in acute kidney injury in mice. Med J Malaysia. 2020;75(Suppl 1):20-3.

42. Nishioka S, Nakano D, Kitada K, Sofue T, Ohsaki H, Moriwaki K, et al. The cyclin-dependent kinase inhibitor p21 is essential for the beneficial effects of renal ischemic preconditioning on renal ischemia/reperfusion injury in mice. Kidney Int. 2014;85(4):871-9.

43. Megyesi J, Andrade L, Vieira JM Jr, Safirstein RL, Price PM. Positive effect of the induction of p21WAF1/CIP1 on the course of ischemic acute renal failure. Kidney Int. 2001;60(6):2164-72.

44. Koyano T, Namba M, Kobayashi T, Nakakuni K, Nakano D, Fukushima M, et al. The p21 dependent G2 arrest of the cell cycle in epithelial tubular cells links to the early stage of renal fibrosis. Sci Rep. 2019;9(1):12059.

45. Li Z, Qiu R, Qiu X, Tian T. SNHG6 promotes tumor growth via repression of P21 in colorectal cancer. Cell Physiol Biochem. 2018;49(2):463-78.

46. Cai G, Zhu Q, Yuan L, Lan Q. LncRNA SNHG6 acts as a prognostic factor to regulate cell proliferation in glioma through targeting p21. Biomed Pharmacother. 2018;102:452-7.

47. Ruan J, Zheng L, Hu N, Guan G, Chen J, Zhou X, et al. Long noncoding RNA SNHG6 promotes osteosarcoma cell proliferation through regulating p21 and KLF2. Arch Biochem Biophys. 2018;646:128-36.

48. Zhao L, Hu K, Cao J, Wang P, Li J, Zeng K, et al. lncRNA miat functions as a ceRNA to upregulate sirt1 by sponging miR-22-3p in HCC cellular senescence. Aging (Albany NY). 2019;11(17):7098-122.

49. Tripathi V, Shen Z, Chakraborty A, Giri S, Freier SM, Wu X, et al. Long noncoding RNA MALAT1 controls cell cycle progression by regulating the expression of oncogenic transcription factor B-MYB. PLoS Genet. 2013;9(3):e1003368.

50. Zhang Y, Tang X, Shi M, Wen C, Shen B. MiR-216a decreases MALAT1 expression, induces G2/M arrest and apoptosis in pancreatic cancer cells. Biochem Biophys Res Commun. 2017;483(2):816-22.

51. Li Y, Liu YD, Chen SL, Chen X, Ye DS, Zhou XY, et al. Down-regulation of long non-coding RNA MALAT1 inhibits granulosa cell proliferation in endometriosis by up-regulating P21 via activation of the ERK/MAPK pathway. Mol Hum Reprod. 2019;25(1):17-29.

52. Ji DG, Guan LY, Luo X, Ma F, Yang B, Liu HY. Inhibition of MALAT1 sensitizes liver cancer cells to 5-flurouracil by regulating apoptosis through IKKalpha/ NF-kappaB pathway. Biochem Biophys Res Commun. 2018;501(1):33-40.
53. Alipoor FJ, Asadi MH, Torkzadeh-Mahani M. MIAT lncRNA is overexpressed in breast cancer and its inhibition triggers senescence and G1 arrest in MCF7 cell line. J Cell Biochem. 2018;119(8):6470-81.

54. Chang L, Yuan Y, Li C, Guo T, Qi H, Xiao Y, et al. Upregulation of SNHG6 regulates ZEB1 expression by competitively binding miR-101-3p and interacting with UPF1 in hepatocellular carcinoma. Cancer Lett. 2016;383(2):183-94.

55. Wang X, Lai Q, He J, Li Q, Ding J, Lan Z, et al. LncRNA SNHG6 promotes proliferation, invasion and migration in colorectal cancer cells by activating TGF-beta/Smad signaling pathway via targeting UPF1 and inducing EMT via regulation of ZEB1. Int J Med Sci. 2019;16(1):51-9.

56. Meng XM, Nikolic-Paterson DJ, Lan HY. TGF-beta: the master regulator of fibrosis. Nat Rev Nephrol. 2016;12(6):325-38.

57. Chen L, Zhang D, Yu L, Dong H. Targeting MIAT reduces apoptosis of cardiomyocytes after ischemia/reperfusion injury. Bioengineered. 2019;10(1):121-32.

58. Qu X, Du Y, Shu Y, Gao M, Sun F, Luo S, et al. MIAT is a pro-fibrotic long non-coding RNA governing cardiac fibrosis in post-infarct myocardium. Sci Rep. 2017;7:42657.

59. Li Q, Pang L, Yang W, Liu X, Su G, Dong Y. Long noncoding RNA of myocardial infarction associated transcript (LncRNA-MIAT) promotes diabetic retinopathy by upregulating transforming growth factor-beta1 (TGFbeta1) signaling. Med Sci Monit. 2018;24:9497-503.

60. Bijkerk R, Au YW, Stam W, Duijs J, Koudijs A, Lievers $\mathrm{E}$, et al. Long non-coding RNAs rian and miat mediate myofibroblast formation in kidney fibrosis. Front Pharmacol. 2019;10:215.

61. Zhou L, Xu DY, Sha WG, Shen L, Lu GY, Yin X. Long non-coding MIAT mediates high glucose-induced renal tubular epithelial injury. Biochem Biophys Res Commun. 2015;468(4):726-32.

62. Tian $\mathrm{H}, \mathrm{Wu}$ M, Zhou P, Huang $\mathrm{C}$, Ye C, Wang L. The long non-coding RNA MALAT1 is increased in renal ischemia-reperfusion injury and inhibits hypoxiainduced inflammation. Ren Fail. 2018;40(1):527-33.

63. Su M, Hu X, Lin J, Zhang L, Sun W, Zhang J, et al. Identification of candidate genes involved in renal ischemia/ reperfusion injury. DNA Cell Biol. 2019;38(3):256-62.

64. Zhao J, Sun BK, Erwin JA, Song JJ, Lee JT. Polycomb proteins targeted by a short repeat RNA to the mouse X chromosome. Science. 2008;322(5902):750-6.

65. Davidovich C, Wang X, Cifuentes-Rojas C, Goodrich KJ, Gooding AR, Lee JT, et al. Toward a consensus on the binding specificity and promiscuity of PRC2 for RNA. Mol Cell. 2015;57(3):552-8.

66. Veneti Z, Gkouskou KK, Eliopoulos AG. Polycomb repressor complex 2 in genomic instability and cancer. Int J Mol Sci. 2017;18(8):1657.

67. Zhao Z, Liu B, Li B, Song C, Diao H, Guo Z, et al. Inhibition of long noncoding RNA IGF2AS promotes angiogenesis in type 2 diabetes. Biomed Pharmacother. 2017;92:445-50.

68. Zhang X, Chen K, Song C, Song C. Inhibition of long non-coding RNA IGF2AS has profound effect on inducing neuronal growth and protecting local-anesthetic 
induced neurotoxicity in dorsal root ganglion neurons. Biomed Pharmacother. 2016;82:298-303.

69. Chen Q, Sun T, Wang F, Gong B, Xie W, Ma M, et al. Long noncoding RNA IGF2AS is acting as an epigenetic tumor suppressor in human prostate cancer. Urology. 2019;124(310):e1-8.

70. Duart-Garcia CPP, Bruggmann R, Simillion CAMV, Keller I, Andersson G, Braunschweig MH. Evidence for two protein coding transcripts at the Igf2as locus. Gene Reports. 2016;4:60-6.

71. Duart-Garcia C, Braunschweig MH. The Igf2as transcript is exported into cytoplasm and associated with polysomes. Biochem Genet. 2013;51(1-2):119-30.

72. Andergassen D, Muckenhuber M, Bammer PC, Kulinski TM, Theussl HC, Shimizu T, et al. The Airn lncRNA does not require any DNA elements within its locus to silence distant imprinted genes. PLoS Genet. 2019;15(7):e1008268.

73. Matsuzaki T, Morisaki T, Sugimoto W, Yokoo K, Sato D, Nonoguchi $\mathrm{H}$, et al. Altered pharmacokinetics of cationic drugs caused by down-regulation of renal rat organic cation transporter 2 (Slc22a2) and rat multidrug and toxin extrusion 1 (Slc47a1) in ischemia/reperfusion-induced acute kidney injury. Drug Metab Dispos. 2008;36(4):649-54.

74. Liu L, Yu D, Shi H, Li J, Meng L. Reduced lncRNA Aim enhances the malignant invasion of triple-negative breast cancer cells mainly by activating Wnt/beta-catenin/ mTOR/PI3K signaling. Pharmazie. 2017;72(10):599-603.

75. Wei Q, Zhao J, Zhou X, Yu L, Liu Z, Chang Y. Propofol can suppress renal ischemia-reperfusion injury through the activation of PI3K/AKT/mTOR signal pathway. Gene. 2019;708:14-20.

76. Kuncewitch M, Yang WL, Corbo L, Khader A, Nicastro J, Coppa GF, et al. WNT agonist decreases tissue damage and improves renal function after ischemia-reperfusion. Shock. 2015;43(3):268-75.

77. Kohn M, Pazaitis N, Huttelmaier S. Why YRNAs? About versatile RNAs and Their Functions. Biomolecules. 2013;3(1):143-56.

78. Christov CP, Trivier E, Krude T. Noncoding human Y RNAs are overexpressed in tumours and required for cell proliferation. Br J Cancer. 2008;98(5):981-8.

79. Kowalski MP, Krude T. Functional roles of non-coding Y RNAs. Int J Biochem Cell Biol. 2015;66:20-9.

80. Reed JH, Sim S, Wolin SL, Clancy RM, Buyon JP. Ro60 requires Y3 RNA for cell surface exposure and inflammation associated with cardiac manifestations of neonatal lupus. J Immunol. 2013;191(1):110-6.

81. Bernardes de Jesus B, Marinho SP, Barros S, SousaFranco A, Alves-Vale C, Carvalho T, et al. Silencing of the lncRNA Zeb2-NAT facilitates reprogramming of aged fibroblasts and safeguards stem cell pluripotency. Nat Commun. 2018;9(1):94.

82. Jiang X, Li D, Shen W, Shen X, Liu Y. LncRNA NEAT1 promotes hypoxia-induced renal tubular epithelial apoptosis through downregulating miR-27a-3p. J Cell Biochem. 2019;120(9):16273-82.

83. Li C, Liu YF, Huang C, Chen YX, Xu CY, Chen Y. Long noncoding RNA NEAT1 sponges miR-129 to modulate renal fibrosis by regulation of collagen type I. Am J Physiol Renal Physiol. 2020;319(1):F93-105.
84. Chodroff RA, Goodstadt L, Sirey TM, Oliver PL, Davies $\mathrm{KE}$, Green ED, et al. Long noncoding RNA genes: conservation of sequence and brain expression among diverse amniotes. Genome Biol. 2010;11(7):R72.

85. Wang Y, Davies KJ, Melendez JA, Crawford DR. Characterization of adapt33, a stress-inducible riboregulator. Gene Expr. 2003;11(2):85-94.

86. Geng X, Lavado A, Lagutin OV, Liu W, Oliver G. Expression of Six3 Opposite Strand (Six3OS) during mouse embryonic development. Gene Expr Patterns. 2007;7(3):252-7.

87. Ramos AD, Diaz A, Nellore A, Delgado RN, Park $\mathrm{KY}$, Gonzales-Roybal G, et al. Integration of genomewide approaches identifies lncRNAs of adult neural stem cells and their progeny in vivo. Cell Stem Cell. 2013;12(5):616-28.

88. Rapicavoli NA, Poth EM, Zhu H, Blackshaw S. The long noncoding RNA Six3OS acts in trans to regulate retinal development by modulating Six3 activity. Neural Dev. 2011;6:32.

89. Shan K, Li CP, Liu C, Liu X, Yan B. RNCR3: A regulator of diabetes mellitus-related retinal microvascular dysfunction. Biochem Biophys Res Commun. 2017;482(4):777-83.

90. Shan K, Jiang Q, Wang XQ, Wang YN, Yang H, Yao MD, et al. Role of long non-coding RNA-RNCR3 in atherosclerosis-related vascular dysfunction. Cell Death Dis. 2016;7(6):e2248.

91. Fu Q, Li S, Zhou Q, Yalikun K, Yisireyili D, Xia M. Low LINC00599 expression is a poor prognostic factor in glioma. Biosci Rep. 2019;39(4):BSR20190232.

92. Tian CDY, Jin Y, Shi S, Bi H. Long non-coding RNA RNCR3 promotes prostate cancer progression through targeting miR-185-5p. Am J Transl Res. 2018;10(5):1562-70.

93. Chi JR, Yu ZH, Liu BW, Zhang D, Ge J, Yu Y, et al. SNHG5 promotes breast cancer proliferation by sponging the miR-154-5p/PCNA axis. Mol Ther Nucleic Acids. 2019;17:138-49.

94. Dutta S, Sengupta P. Men and mice: relating their ages. Life Sci. 2016;152:244-8.

95. Flurkey K, M. Currer J, Harrison DE. Chapter 20 - Mouse models in aging research. In: Fox JG, Davisson MT, Quimby FW, Barthold SW, Newcomer CE, Smith AL, editors. The mouse in biomedical research (Second Edition). Burlington: Academic Press. 2007. 637-72

96. Jang HR, Park JH, Kwon GY, Park JB, Lee JE, Kim DJ, et al. Aging has small effects on initial ischemic acute kidney injury development despite changing intrarenal immunologic micromilieu in mice. Am J Physiol Renal Physiol. 2016;310(4):F272-83.

97. Miya M, Maeshima A, Mishima K, Sakurai N, Ikeuchi H, Kuroiwa T, et al. Age-related decline in label-retaining tubular cells: implication for reduced regenerative capacity after injury in the aging kidney. Am J Physiol Renal Physiol. 2012;302(6):F694-702.

Publisher's note Springer Nature remains neutral with regard to jurisdictional claims in published maps and institutional affiliations. 